\title{
PENGARUH WORD OF MOUTH TERHADAP PURCHASE INTENTIONDENGAN BRAND IMAGE DAN PERCEIVED SERVICE QUALITY SEBAGAI VARIABEL INTERVENING PADA PROGRAM KPR BERSUBSIDI DI SURABAYA
}

\author{
Carolus Indra \\ Praktisi Pemasaran di Surabaya \\ Email: carolusindra99@gmail.com
}

\begin{abstract}
Abstrak:Pertumbuhan penduduk di Indonesia sangat pesat, terutama di kota-kota besar seperti Surabaya. Dengan perkembangan yang ada kebutuhan akan tempat tinggal juga semakin tinggi. Produk Kredit Pemilikan Rumah adalah salah satu Produk yang sangat dicari oleh konsumen.Penelitian ini bertujuan untuk menganalisa pengaruh dari Word of mouth communication terhadap Purchase intention pada KPR bersubsidi di Surabaya dengan Brand Image dan Perceived service quality sebagai variabel intervening. Penelitian ini dilaksanakan dengan menyebarkan kuisioner kepada 150 responden calon pelanggan KPR bersubsidi di Surabaya. Teknik analisa yang digunakan adalah teknik analisis kuantitatif dengan metode path analysis.
\end{abstract}

Kata kunci:Word of mouth communication, brand image, perceived service quality, purchase intention.

\begin{abstract}
Population growth in Indonesia is very rapid, especially in big cities such as Surabaya. With the existing development of the need for shelter is also higher. Home Ownership Credit Product is one of the most sought after product by consumers. This study aims to analyze the influence of Word of Mouth Communication on Purchase Intention on subsidized KPR in Surabaya with Brand Image and Perceived Service Quality as intervening variable. This study was conducted by distributing questionnaires to 150 respondents of prospective subsidized KPR in Surabaya. Analysis technique used is quantitative analysis technique with path analysis method.
\end{abstract}

Keywords: Word of mouth communication, brand image, perceived service quality, purchase intention.

\section{PENDAHULUAN}

Rumah merupakan salah satu hal yang sangat diperlukan bagi setiap orang, karena rumah adalah papan yang berarti kebutuhan primer yang harus dipenuhi. Jika kebutuhan primer tersebut tidak dipenuhi maka manusia tidak dapat hidup dengan sebagaimana mestinya. Fungsi dari rumah sendiri adalah sebagai tempat berlindung dan tempat berkumpul bersama keluarga.

Bersamaan dengan perkembangan properti tempat tinggal khususnya rumah pada saat ini di Indonesia, sudah banyak developer yang membangun dan menjual rumah dengan harga yang beragam, mulai dari harga yang terjangkau hingga menjual dengan harga yang sangat tinggi. Data yang dihimpun oleh Surya Tribunnews menyatakan bahwa pertumbuhan ekonomi dari 2015 hingga 2017 sudah mengalami peningkatan dari 4,79 hingga 5,3 persen. Pertumbuhan ekonomi tersebut memberikan dampak pertumbuhan bisnis properti yang cukup baik.

Salah satu kota yang memiliki pertumbuhan bisnis properti yang cukup maju di Indonesia adalah kota Surabaya, karena Surabaya merupakan jantung dari Jawa Timur yang memiliki pertumbuhan ekonomi yang tinggi serta memiliki lahan yang lebih luas dari Jakarta. Menurut Liputan6 tingkat pertumbuhan ekonomi di Surabaya berada di atas pertumbuhan ekonomi nasional yaitu 7,6 persen yang terjadi karena banyaknya perkembangan pembangunan properti di Surabaya. Besarnya perkembangan properti di Surabaya dapat memberikan kesempatan bagi setiap masyarakat untuk memiliki rumah sendiri.

Cara untuk memiliki rumah terdapat berbagai macam cara yang salah satunya dengan menggunakan program KPR (Kredit Pemilikan Rumah) yang sangat mempermudah masyarakat yang ingin memiliki rumah impian sendiri. KPR merupakan kredit dari bank yang digunakan untuk membeli rumah atau kebutuhan konsumtif lainnya dengan jaminan berupa rumah yang akan dibeli tersebut. Dengan menggunakan KPR, pembelian rumah dapat diangsur dalam jangka waktu tertentu yang meringankan konsumen yang melakukan pembelian rumah dengan program KPR.

Penyedia program KPR di Surabaya sudah sangat banyak dan memiliki keunggulan masingmasing, diantara beberapa program KPR yang ditawarkan terdapat program KPR bersubsidi yang memiliki bunga lebih rendah dibanding program KPR lainnya. Beberapa bank yang menyediakan program KPR bersubsidi adalah KPR Mandiri, BRI, BTN, 
BNI, dan bank Jatim (Detik Finance, 2015). Program KPR bersubsidi adalah kredit pemilikan rumah program kerjasama dengan Kementrian Pekerjaan Umum dan Perumahan Rakyat dengan suku bunga rendah dan tetap, serta memiliki cicilan yang ringan untuk membantu masyarakat berpenghasilan rendah untuk tetap dapat memiliki rumah layak huni.

Program KPR bersubsidi sedang mengalami peningkatan karena dibantu oleh pemerintah melalui kementrian pekerjaan umum dan perumahan rakyat meminta kepada bank yang memberikan program KPR bersubsidi untuk lebih gencar menyalurkan kredit pemilikan rumah bagi masyarakat berpenghasilan rendah dan pegawai negeri sipil (bisnis.com, 2015).

Dengan adanya word of mouth perusahaan ingin mengetahui pengaruh yang didapati terhadap purchase intention, sehingga dengan pengaruh brand image, dan perceived service quality, pasti minat beli dari calon pelangan meningkat.

Berdasarkan latar belakang diatas, maka dari itu peneliti ingin meneliti pengaruh word of mouth terhadap purchase intention melalui brand image \& perceived service quality pada penyedia program KPR bersubsidi yaitu BTN, Mandiri, BRI, BNI, dan Bank Jatim di Surabaya. Peneliti berharap penelitian ini bisa memberi gambaran lebih mengenai pengaruh dari word of mouth dalam meningkatkan purchase intention, sehingga konsumen memiliki minat beli yang lebih baik.

\section{LANDASAN TEORI}

\section{A. Word OfMouth}

Promosi adalah salah satu strategi yang digunakan perushaan untuk memberitahukan atau menawarkan barang atau jasa untuk menarik calon konsumen untuk membeli ataupun mengkonsumsinya. Dengan adanya promosi produsen mengharapkan adanya kenaikan penjualan. Salah satu dimensi dari promosi adalah word of mouth yang digunakan untuk melakukan promosi secara luas dari mulut ke mulut.

Menurut Solomon (2002), word of mouth adalah informasi mengenai suatu produk yang diteruskan dari satu individu ke individu lain. Proses komunikasi yang paling sering terjadi antar manusia adalah melalui muluk ke mulut. Setiap orang berbicara dan bertukar informasi mengenai suatu produk dengan orang lain setiap saat. Word of mouth terkadang ada yang berbicara positif dari suatu produk dan terkadang bias juga berbicara negatif. Sebagian besar dari calon konsumen mendapatkan informasi berdasarkan orang-orang disekitar seperti konsumen yang telah menggunakan produk ataupun dari orang- orang terdekat, hal tersebut berpengaruh dengan word of mouth yang lebih dapat dipercaya karena berasal dari sumber yang tidak terikat oleh perusahaan tertentu dibandingkan dengan saluran pemasaran yang lebih formal.

\section{B. Brand Image}

Citra yang baik untuk sebuah merek adalah hal yang cukup penting bagi perusahaan. Di mana citra yang baik dari sebuah merek akan membuat konsumen memiliki pemikiran yang baik terhadap merek tersebut. Hal ini pasti sangat diinginkan oleh perusahaan agar merek yang dimiliki memiliki citra yang baik di mata konsumen. Ketika konsumen mendapatkan nilai lebih dari suatu merek tertentu maka konsumen akan mendapati citra yang baik atas merek tersebut.

Brand image dikenal sebagai salah satu konsep terpenting dalam marketing dan ditetapkan sebagai persepsi tentang suatu merek yang mencerminkan brand asosiasi yang tersimpan di ingatan konsumen (Keller, 1993).Dasar pemikiran dari brand image yang kuat menciptakan kepercayaan, stabilitas, dan diferensiasi (Grace and O'Cass, 2005), terutama di pasar yang bergejolak, matang dan kompetitif.

\section{Perceived Service Quality}

Perceived service quality adalah evaluasi penilaian konsumen mengenai peforma servis yang unggul (Zeithaml, 2000). Dengan adanya pelayanan yang unggul membuat konsumen menjadi puas serta dapat menceritakan pengalaman mereka tersebut kepada masyarakat ataupun kepada calon konsumen. Sehingga masyarakat memiliki persepsi yang baik juga terhadap kualitas layanan yang diberikan oleh suatu perusahaan tersebut.

Perceived service quality dapat didefinisikan sebagai persepsi konsumen terhadap keseluruhan kualitas atau keunggulan suatu produk atau jasa layanan yang berkaitan dengan apa yang diharapkan oleh konsumen. Perceived service quality merupakan persepsi yang muncul dari konsumen ataupun calon konsumen sehingga tidak dapat ditentukan secara obyektif.

\section{Purchase Intention}

Minat beli merupakan sebuah kunci penting bagi konsumen ketika mereka sedang mempertimbangkan dan mengevaluasi produk tertentu. Minat beli adalah sebuah alat yang efektif dalam memprediksi proses pembelian. Saat konsumen memutuskan untuk membeli sebuah produk, mereka secara tidak langsung diarahkan oleh keinginan/minatnya. 
Menurut Blackwell et al. (2001), definisi dari purchase intention adalah apa yang seseorang pikir mereka akan beli. Dari definisi ini didapatkan jika purchase intention adalah fase dimana seseorang sebelum melakukan pembelian dan masih berencana ataupun berminat untuk membeli.

\section{E. Penelitian Terdahulu}

Penelitian terdahulu yang dilakukan dalam jurnal "Determining the Impact of Ewom on Brand Image and Purchase Intention through Adoption of Online Opinions" (Naimatullah Charo, Pershant Sharma, Saadullah Shaikh, Abdul Haseeb,and Muhammad Zohaib Sufya, 2015). Penelitian ini bertujuan untuk meneliti impact yang terjadi dengan opini online pada word of mouth terhadap brand image.Hasil dari penelitian ini menyatakan bahwa efek dari $e W O M$ memiliki efek yang signifikan dalam mempengaruhi Brand image.

\section{F. Kerangka Konseptual}

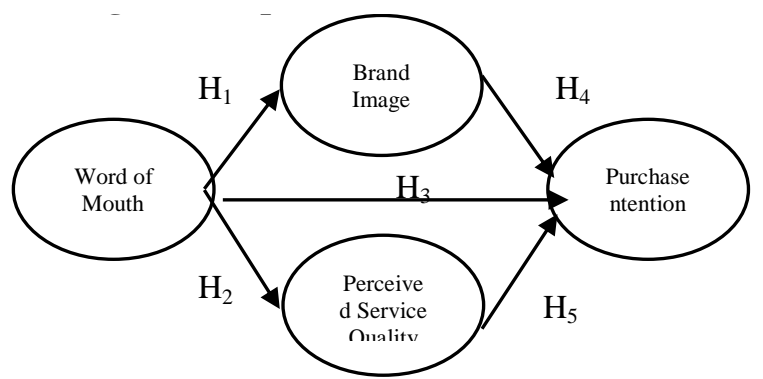

Gambar 1. Kerangka Konseptual

\section{G. Hipotesa}

H1: Word Of Mouth berpengaruh positif terhadap Brand Image

H2: Word Of Mouth berpengaruh positif terhadap Perceived Service Quality

H3: Word Of Mouth berpengaruh positif terhadap Purchase Intention

H4: Brand Image berpengaruh positif terhadap Purchase Intention

H5: Perceived Service Quality berpengaruh positif terhadap Purchase Intention

\section{METODOLOGI PENELITIAN}

\section{A. Populasi, dan Sampel}

Jenis penelitian yang digunakan dalam penelitian ini adalah kuantitaif kausal. Adapun populasi dalam penelitian ini adalah masyarakat kelas menengah bawah yang berminat menggunakan program KPR bersubsidi di Surabaya.Teknik pengambilan sampel pada penelitian ini menggunakan teknik non probability sampling, dimana semua populasi tidak memiliki peluang yang sama untuk menjadi responden dan pengambilan sampel didasarkan pada pertimbangan peneliti (Churchill, 2005). Jenis non probability sampling yang digunakan dalam penelitian ini adalah purposive sampling dimana peneliti melakukan penilaian untuk memilih anggota populasi yang merupakan calon pengguna KPR yang berdomisili di Surabaya yang memiliki kriteria yang telah ditentukan oleh peneliti, seperti penghasilan perbulan, usia, pekerjaan.

\section{B. Definisi Operasional Variabel}

1. Word of Mouth $\left(\mathrm{X}_{1}\right)$

a) Attribute of source Kemamouan dari pemberi informasi untuk meyakinkan

b) Rate of activity Kemampuan pemberi informasi untuk memberikan informasi secara rutin

c) Personal relevance Kemampuan pemberi informasi untuk memberikan informasi yang relevan dan persuasif

d) Polarity Kemampuan pemberi informasi untuk memberikan informasi yang positif atau negatif

2. Brand image $\left(\mathrm{Y}_{1}\right)$

a) Brand strength

Seberapa kuat merek program KPR ada di benak konsumen

b) Brand favorability

Rasa suka terhadap program KPR kelas menengah

c) Brand uniqueness

seberapa unik merek Program KPR kelas menengah dibanding program lain

3. Perceived service quality (Y2)

a) Kualitas interaksi adalah kualitas yang diberikan pada saat proses pelayanan dari perusahaan kepada konsumen

b) Kualitas lingkungan fisik merupakan kualitas yang ada pada lingkungan ketika proses pelayanan sedan dilaksanakan

c) Kualitas hasil merupakan suatu hal yang didapatkan konsumen ketika proses layanan telah selesai diberikan.

4. Purchase Intention

a) Transactional interest merupakan kencederungan konsumen untuk membeli sebuah produk

b) Preferental Interest merupakan perilaku konsumen yang memiliki pembanding lain sebelum melakukan pembelian

c) Exploratory Interest merupakan perilaku konsumen yang selalu mencari informasi terlebih dahulu mengenai produk yang diminatinya. 


\section{Teknik Analisa Data}

a. Path Analysis

Pengujian hipotesis yang ada pada penelitian ini dilakukan dengan menggunakan teknik path analysis untuk menunjukkan adanya hubungan yang kuat dengan variabel-variabel yang diuji. Teknik path analysis digunakan untuk melukiskan dan menguji model hubungan antar variabel yang berbentuk sebab akibat (Sugiyono, 2007). Pengajuan statistik pada model path analysis dilakukan dengan menggunakan metode partial least square. Partial Least Square (PLS) adalah bagian dari SEM. PLS Merupakan teknik terbaru yang banyak diminati karena tidak membutuhkan distribusi normal atau dapat dikatakan sebuah penelitian dengan jumlah sampel yang sedikit.Salah satu kelebihan PLS-SEM adalah mampu menangani model yang kompleks dengan multiple variabel eksogen dan endogen dengan banyak indikator, dapat digunakan pada sampel dengan jumlah kecil, dan data distribusi yang condong (Abdillah \& Hartono, 2015).

b. T-test

Di dalam penelitian ini terdapat variabel intervening yaitu penghubung antara variabel dependen dan variabel independen. Pengujian hipotesis mediasi (variabel intervening) dapat dilakukan dengan prosedur $t$-test. Pengujian $t$-test digunakan untuk mendapatkan nilai t-statistik yang diperlukan apabila peneliti ingin melakukan uji hipotesis, sehingga peneliti dapat mengatakan pengaruh sebuah variabel dapat dikatakan memiliki pengaruh yang signifikan atau tidak. T-test dilakukan dengan menggunakan metode bootstrapping.

Metode bootstrappingadalah suatu proses pengujian re-samplingyang dilakukan oleh sistem komputer untuk mengukur akurasi pada sampleestimate. Bootstraping digunakan untuk mengukur akurasi pada sample. Apabila nilai bootstrap lebih dari (>) 1.96 maka dinyatakan bahwa variabel tersebut memiliki pengaruh yang signifikan sedangkan apabila nilai bootstrap lebih rendah $(<)$ dari 1.96, maka dinyatakan pengaruh variabel tersebut lemah (Abdillah \& Hartono, 2015).

c. Statistik Deskriptif

Statistik deskriptifdigunakan untuk menyajikan data secara deskriptif yangmenggambarkan karakteristik responden serta jawaban-jawaban responden sehingga mampu digunakan sebagai kesimpulan dari hasil kuisioner yang sudah disebarkan selama penelitian ini.

\section{ANALISA DAN PEMBAHASAN}

\section{A. Analisa Deskriptif}

Tabel 1. Analisa Deskriptif Dimensi Rate of Activity

\begin{tabular}{|c|c|c|c|c|c|c|c|}
\hline \multirow{2}{*}{ Indikator } & \multicolumn{5}{|c|}{ Jawaban } & \multirow{2}{*}{ Mean } & \multirow{2}{*}{ Std. Dev } \\
\hline & STS & TS & $\mathbf{N}$ & $\mathbf{S}$ & SS & & \\
\hline (X.1.3) & 0 & 8 & 48 & 76 & 18 & 3,693 & 0,750 \\
\hline (X.1.4) & 1 & 1 & 41 & 88 & 19 & 3,820 & 0,676 \\
\hline
\end{tabular}

Rate of Activity merupakan seberapa sering responden mendapatkan informasi tentang KPR bersubsidi. Responden sendiri dapat mencari informasi ataupun mendapatkan informasi. Dari Tabel 1 dimensi yang menjelaskan tentang informasi yang sering didapat dari teman memiliki mean yang cukup tinggi pada indikator X1.4 sebesar 3,820. Hal tersebut terjadi karena pada indikator sebelumnya diketahui jika mayoritas responden mendapatkan informasi yang sangat berpengaruh dari teman, apalagi teman merupakan orang terdekat yang dapat dipercaya dan didukung juga teman yang sudah pernah mengambil program KPR bersubsidi dan sudah memiliki pengalaman akan program KPR bersubsidi tersebut. Sehingga nilai mean dari indikator X1.4 dapat memiliki nilai yang tinggi.

Sebanyak $71,33 \%$ responden menjawab setuju terhadap indikator X1.4 yang berisi $58,66 \%$ responden menjawab "setuju" dan $12,67 \%$ menjawab "sangat setuju" hal ini terjadi dengan informasi yang berasal dari teman lebih sering didapatkan dan dapat dengan cepat menyebarkan informasi tentang KPR bersubsidi.

Indikator kedua adalah X1.3 yang merupakan informasi yang sering didapatkan dengan mencari sendiri. Indikator ini memiliki mean sebesar 3,693 yang walaupun tidak sebesar indikator X1.4 tetapi responden yang mencari informasi sendiri juga cukup banyak yang setuju dan dapat ditarik kesimpulan jika KPR bersubsidi ini sering dicari oleh calon pelanggannya. Hal ini terjadi karena calon pelanggan ada beberapa yang tidak setuju jika mencari informasi terbaru dari teman, karena itu calon pelanggan ada yang langsung mencari informasi secara langsung dengan cara membuka website dari masing-masing penyedia KPR bersubsidi dan dengan cara langsung ke kantor KPR bersubsidi agar bisa mendapat informasi sendiri dengan lebih jelas.

Brand Strength merupakan seberapa kuat dari merek yang dimiliki KPR bersubsidi di benak calon pelanggan. Dimensi ini dapat diukur dengan persepsi calon pelanggan mengenai KPR bersubsidi tersebut. Tabel 2 menjelaskan jika kedua indikator tersebut sangat berkaitan dan terbukti dengan mean dari Y1.1 
sebesar 3,793 dan Y1.2 sebesar 3,800 yang tidak berbeda jauh. Hal ini terbangun oleh adanya persepsi calon pelanggan atas citra merek yang dimiliki oleh KPR bersubsidi.

Tabel 2. Analisa Deskriptif Dimensi Brand Strength

\begin{tabular}{lccccccc}
\hline \multirow{2}{*}{ Indikator } & \multicolumn{9}{c}{ Jawaban } & \multirow{2}{*}{ Mean } & \multirow{2}{*}{ Std. Dev. } \\
\cline { 2 - 7 } & STS & TS & $\mathbf{N}$ & S & SS & & \\
\hline (Y.1.1) & 1 & 9 & 36 & 78 & 26 & 3,793 & 0,822 \\
$($ Y.1.2) & 1 & 10 & 36 & 74 & 29 & 3,800 & 0,851 \\
\hline
\end{tabular}

Dengan Y1.1 sebesar 3,793 maka calon pelanggan memiliki persepsi jika KPR bersubsidi sudah memiliki citra yang baik di mata calon pelanggan tersebut. Seperti KPR BTN yang sudah menyediakan KPR bersubsidi selama bertahun-tahun sehingga responden memiliki pandangan yang baik terhadap KPR tersebut. Sendangkan dengan Y1.2 sebesar 3,800 maka calon pelanggan pun setuju jika KPR bersubsidi mudah dijangkau oleh mereka.

Mayoritas dari responden setuju jika KPR bersubsidi mudah dijangkau maka akan membentuk persepsi juga jika KPR bersubsidi memiliki citra yang baik di mata calon pelanggan. Sehingga kedua mean pada indikator ini dapat memiliki nilai yang cukup tinggi.

Tabel 3. Analisa Deskriptif Dimensi Kualitas Interaksi

\begin{tabular}{cccccccc}
\hline \multirow{2}{*}{ Indikator } & \multicolumn{9}{c}{ Jawaban } & \multirow{2}{*}{ Mean } & \multirow{2}{*}{ Std. Dev. } \\
\cline { 2 - 7 } & STS & TS & N & S & SS & & \\
\hline (Y.2.1) & 0 & 3 & 41 & 83 & 23 & 3,840 & 0,696 \\
(Y.2.2) & 0 & 13 & 44 & 64 & 29 & 3,727 & 0,874 \\
\hline
\end{tabular}

Kualitas Interaksi merupakan bentuk interaksi yang diterima oleh responden saat berhadapan dengan penyedia program KPR bersubsidi. Dari Tabel 3 sebesar 3,840 yang memiliki arti jika pelayanan yang diterima oleh calon konsumen KPR bersubsidi ramah. Dengan nilai mean yang cukup tinggi tersebut dapat membuat $70,67 \%$ responden setuju dan nyaman dengan interaksi yang diberikan. Interaksi yang diberikan oleh karyawan KPR bersubsidi kepada calon pelanggan diaktakan ramah karena calon pelanggan merupakan orang awam yang masih belum mengerti akan KPR sehingga dengan ramah calon pelanggan disambut untuk dapat memahami tentang KPR bersubsidi tersebut.

Indikator Y2.2 tentang pelayanan yang diberikan KPR bersubsidi lengkap memiliki mean yang cukup tinggi juga sebesar 3,727. Responden setuju dan merasakan jika pelayanan yang diberikan oleh KPR bersubsidi lengkap. Hal ini terjadi karena KPR bersubsidi memiliki target konsumen yang merupakan konsumen baru, sehingga pelayanan yang diberikan haruslah lengkap agar calon konsumen tidak salah paham menafsirkan tentang KPR bersubsidi.

Kedua indikator ini memiliki mean yang cukup tinggi karena pelayanan yang ramah dan lengkap yang diberikan kepada calon pelanggan dari KPR bersubsidi. Serta dari pengalaman yang diberikan oleh konsumen yang pernah menggunakan KPR bersubsidi.

Tabel 4. Analisa Deskriptif Dimensi Transactional Interest

\begin{tabular}{cccccccc}
\hline \multirow{2}{*}{ Indikator } & \multicolumn{9}{c}{ Jawaban } & \multirow{2}{*}{ Mean } & \multirow{2}{*}{ Std. Dev. } \\
\cline { 2 - 7 } & STS & TS & N & S & SS & & \\
\hline$(Z .1 .1)$ & 0 & 4 & 38 & 84 & 24 & 3,853 & 0,708 \\
$(Z .1 .2)$ & 0 & 9 & 48 & 72 & 21 & 3,700 & 0,784 \\
\hline
\end{tabular}

Transactional Interest merupakan ketertarikan dari calon pelanggan KPR bersubsidi untuk memilih program KPR bersubsidi. Ketertarikan ini berdasarkan dari minat calon pelanggan. Pada Tabel 4 indikator Z1.1 memiliki mean yang besar dengan nilai 3,853 yang berarti calon pelanggan memiliki minat untuk menggunakan KPR bersubsidi karena pengaruh dari orang lain yang diterima dan membentuk persepsi dari calon pelanggan terhadap KPR bersubsidi.

Indikator kedua yaitu Z1.2 memiliki nilai mean yang cukup tinggi juga sebesar 3,7 yang menjelaskan jika responden pun memilih KPR bersubsidi tanpa ada pertimbangan KPR lainnya dan hanya 9 responden yang tidak setuju dengan agumen ini.

\section{B. Evaluasi Path Coefficient dan Coefficient of Determination $\left(\mathbf{R}^{2}\right)$}

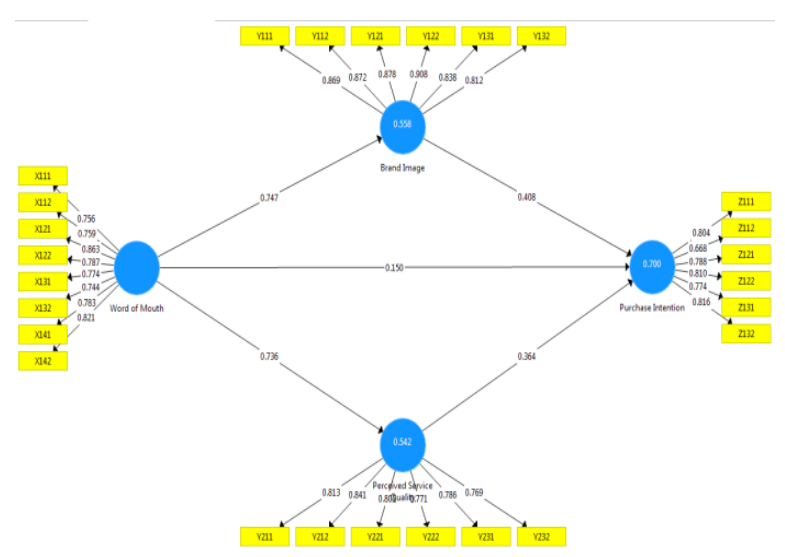

Gambar 2. Path Coefficient dan Coefficient of Determination

Pada analisa path coefficient ini telah dibuktikan bahwa Brand Image dan Perceived Service Quality merupakan variabel intervening dimana memperkuat hubungan antara Word of Mouth dan PurchaseIntention. Dari gambar 2 dapat dijelaskan 
bahwa nilai path coefficient terbesar ditunjukkan dari pengaruh Word of Mouth terhadap Brand Image sebesar 0,747. Sedangkan kontribusi nilai Word of Mouth terhadap Perceived Service Quality sebesar 0,736. Hubungan menuju Purchase Intention terkuat juga didapat ketika Word Of Mouth melewati Brand Image dan menuju Purchase Intention.

Pada hubungan Word of Mouthterhadap Purchase Intention secara langsung memiliki path coefficient senilai 0,150. Lalu ketika hubungan tersebut melalui variabel Brand Image terlebih dahulu, maka nilai dari path coefficient meningkat menjadi 0,304 (= $0,747 \times 0,408$ ). Sehingga hal ini merupakan bukti bahwa Brand Image merupakan variabel intervening yang memperkuat hubungan antara Word of Mouth dengan Purchase Intention.

Selain Brand Image, Perceived Service Quality juga memiliki peranan sebagai variabel intervening dimana memperkuat hubungan antara Word of Mouth dengan Purchase Intention. Diketahui bahwa nilai path coefficient dari hubungan Word of Mouth dengan Purchase Intentionsebesar 0,150. Lalu ketika hubungan tersebut melalui variabel Perceived Service Quality maka nilai tersebut meningkat menjadi $0,267(=0,736$ x 0,364). Sehingga dari hal tersebut menjadi bukti bahwa Perceived Service Quality sebagai variabel intervening memperkuat hubungan yang sudah ada.

Jadi kesimpulan bagi seluruh variabel dalam model ini memiliki path coefficient dengan angka yang positif. Artinya, jika semakin besar nilai path coefficient pada satu variabel independen terhadap variabel dependen, maka semakin kuat juga pengaruh antara variabel independen terhadap variabel dependen tersebut. Namun hubungan Word Of Mouth terhadap Purchase Intention secara langsung memiliki angka yang paling rendah, yaitu 0,150 yang berarti pengaruh Word of Mouth terhadap Purchase Intention sangatlah rendah.

Hubungan Word of Mouth terhadap Purchase Intention secara langsung tidak kuat karena hanya dengan pemasaran dari mulut ke mulut saja tidak dapat mempengaruhi minat beli calon pelanggan dari KPR bersubsidi. Word of Mouth yang baik namun tidak didukung dengan citra merek yang baik dalam KPR bersubsidi maka belum mampu menciptakan Purchase Intention dan Word of Mouth yang baik pula jika tidak didukung dengan Perceived Service Quality yang baik dalam KPR bersubsidi maka belum mampu menciptakan Purchase Intention yang baik. Pada objek penelitian ini sangat dibutuhkan peran Brand Image dan Perceived Service Quality menuju Purchase Intention.
Sementara itu, nilai coefficient of determination $\left(\mathrm{R}^{2}\right)$ yang pada gambar ditunjukkan pada angka di dalam lingkaran variabel Brand Image, Perceived Service Quality, dan Purchase Intention, membuktikan bahwa variabel Brand Image dipengaruhi oleh Word of Mouth dengan nilai varian sebesar 0,558. Artinya, sebanyak 44,2\% lainnya dipengaruhi oleh variabel lain diluar penelitian. Lalu variabel Perceived Service Quality dipengaruhi oleh Word of Mouth dengan nilai varian sebesar 0,542. Artinya pengaruh Word of Mouth terhadap Perceived Service Quality sebesar $54,2 \%$, sedangkan 45,8\% lainnya dijelaskan oleh variabel lain diluar penelitian. Sedangkan variabel Purchase Intention dipengaruhi oleh variabel Word of Mouth, Brand Image, dan Perceived Service Quality dengan nilai varian 0,700. Maka dari itu diketahui bahwa didalam penelitian ini Purchase Intention dipengaruhi sebesar 70\% dimana 30\% terbentuknya Purchase Intention dijelaskan oleh variabel-variabel lain diluar penelitian.

\section{T-statistic}

Tabel 7. T-statistic

\begin{tabular}{ccccc}
\hline & $(\mathbf{O})$ & $(\mathbf{M})$ & $(\mathbf{S T E R R})$ & $\begin{array}{c}\text { T Statistics } \\
(\mathbf{O} / \text { STERR })\end{array}$ \\
\hline$X 1-Y 1$ & 0,747 & 0,748 & 0,042 & 17,939 \\
$X 1-Y 2$ & 0,736 & 0,738 & 0,037 & 19,971 \\
$X-Z$ & 0,150 & 0,143 & 0,087 & 1,727 \\
$Y 1-Z$ & 0,408 & 0,407 & 0,059 & 6,883 \\
$Y 2-Z$ & 0,364 & 0,371 & 0,080 & 4,559 \\
\hline
\end{tabular}

Dengan melihat table 7, dapat diartikan bahwa nilai original sample $(\mathrm{O})$ adalah nilai path coefficient yang menunjukkan kekuatan pengaruh dari satu latent variable ke satu latent variable lainnya. Sedangkan nilai pada kolom sample mean (M) menunjukkan nilai tengah dari path coefficient. Sedangkan standard error (STDERR), menunjukkan nilai error pada sampel mean. Nilai $T$ statistics untuk melihat nilai $\mathrm{T}$ hitung yang akan digunakan untuk pengujian hipotesis, dimana $T$ statistics yang memiliki nilai di atas 1,96 memiliki pengaruh.

\section{Pembahasan}

\section{a. Word of Mouth terhadap Brand Image}

Hasil penelitian ini menunjukkan bahwa variabel Word of Mouth dari KPR Bersubsidi memiliki pengaruh yang terhadap Brand Image dengan hasil nilai uji $T$-statistics $>1,96$ yaitu sebesar 17,939.

KPR bersubsidi pada saat ini gencar melakukan promosi dan salah satu promosinya adalah dengan 
menggunakan Word of Mouth. Apalagi dengan pembangunan yang semakin cepat menjadikan KPR bersubsidi sangat diminati oleh masyarakat. Adapun Word of Mouth sangat mudah untuk didapatkan dan siapa saja dapat menjadi perantara dan penyampaian informasi dapat berlangsung dengan cepat.

Akibat dari Word of Mouth sendiri dapat membentuk suatu persepsi terhadap Brand Image yang ada di benak calon pelanggan KPR bersubsidi. Calon pelanggan pun dapat memilikipandanganterhadap KPR bersubsidi. Sehingga calon pelanggan pun dapat menilai merek dari KPR bersubsidi berdasarkan Word of Mouth yang mereka terima.

Word of Mouth sendiri memiliki nilai path positif terhadap Brand Image sebesar 0,747 dimana merupakan hubungan yang paling kuat dalam penelitian ini. Hal ini menunjukkan bahwa Word of Mouth memiliki pengaruh yang sangat kuat dalam membentuk Brand Image dari calon pelanggan KPR bersubsidi.

\section{b. Word of Mouth terhadap Perceived Service Quality}

Pada hasil penelitian ini dapat dilihat bahwa Word of Mouth tidak hanya memiliki pengaruh yang pada Brand Image, namun berpengaruh pula pada Perceived Service Quality dari KPR bersubsidi dengan nilai uji $T$-statistics $>1,96$ yaitu 19,971. Hasil tersebut membuktikan bahwa Word of Mouth memiliki dampak signifikan bagi Perceived Service Quality yang dimiliki perusahaan.

Word of Mouth yang menjadi bagian utama dalam KPR bersubsidi membutuhkan kualitas layanan yang dapat dirasakan oleh calon pelanggannya agar dapat memberikan layanan yang nyata dan dapat membentuk persepsi dari kualitas layanan yang diberikan oleh penyedia KPR bersubsidi. Ketika Word of Mouth tentang KPR bersubsidi memiliki Word of Mouth yang positif, maka persepsi akan suatu kualitas layanan akan dapat dengan mudah meningkat.

Sebagai dampak Word Of Mouth yang diterima oleh calon pelanggan jika memiliki Word of Mouth yang positif maka menjadikan persepsi dari suatu kualitas layanan bisa ditingkatkan dengan mudah, dan calon pelanggan sudah memiliki persepsi baik atas KPR bersubsidi tersebut. Terlihat jika Perceived Service Quality dari KPR bersubsidi memiliki nilai yang tinggi juga dan dipengaruhi oleh Word of Mouth.

Apabila melihat pada nilai path coefficient, hubungan dari Word of Mouth menuju Perceived Service Quality memiliki nilai sebesar 0,736 yang merupakan hubungan positif. Hal ini berarti keberadaan Word of Mouth dari KPR bersubsidi yang diterima oleh calon pelanggan mampu berperan dalam menciptakan persepsi dari kualitas layanan dalam industri perkreditan rumah.

\section{c. Word of Mouth terhadap Purchase Intention}

Hasil penelitian ini juga menunjukkan bahwa Word of Mouth tidak berpengaruh kuat terhadap Purchase Intention. Pada hasil penelitian ini diketahui bahwa tidak adanya pengaruh kuat tersebut dari hasil uji T-statistics dengan nilai 1,727, yaitu dibawah 1,96. Sehingga diketahui bahwa Word of Mouth tentang KPR bersubsidi yang sampai kepada calon pelanggan pelanggan langsung dapat mempengaruhi minat beli calon pelanggan namun tidak secara baik. Jika dilihat dari nilai path coefficient, hubungan dari Word of Mouth menuju Purchase Intention sebesar 0,150. Word of Mouth memberikan pengaruh namun tidak besar dalam terbentuknya minat beli calon pelanggan secara langsung.

Word of Mouth yang tersampaikan kepada calon pelanggan oleh KPR bersubsidi belum mampu secara langsung dengat kuat meningkatkan minat beli calon pelanggan. Hal ini terjadi karena dalam meningkatkan minat beli calon pelanggan dibutuhkan adanya ikatan yang baik antara calon pelanggan terhadap perusahaan serta persepsi yang dibangun dalam benak calon pelanggan. Word of Mouth saja belum mampu untuk menghadirkan hal tersebut sehingga dibutuhkan adanya pengaruh dari variabel lainnya seperti Brand Image dan Perceived Service Quality.

\section{d. Brand Image terhadapPurchase Intention}

Nilai Brand Image terhadap Purchase Intention pada KPR bersubsidi memiliki nilai $T$-Statistic di atas 1,96, yaitu 6,833. Nilai ini menunjukkan bahwa hubungan antara Brand Image dan Purchase Intention memiliki nilai yang signifikan.

Brand Image merupakan pandangan calon pelanggan KPR bersubsidi terhadap program KPR bersubsidi. Hubungan ini dipersepsikan dengan kepercayaan calon pelanggan terhadap program KPR bersubsidi sehingga dapat memunculkan minat beli dari suatu calon pelanggan terhadap KPR bersubsidi. Brand Image yang baik sendiri akan membuat calon pelanggan lebih percaya terhadap KPR bersubsidi dan dapat membentuk Purchase Intention yang baik juga.

Nilai path coefficient dari Brand Image terhadap Purchase Intention adalah 0,408. Nilai ini menunjukkan adanya pengaruh yang cukup kuat dari Brand Image terhadap Purchase Intention. Calon pelanggan KPR bersubsidi yang sudah memiliki persepsi baik tentang citra dari merek KPR bersubsidi maka akan muncul minat beli terhadap KPR bersubsidi. 


\section{e. Perceived Service Quality terhadap Purchase Intention}

Dari hasil analisa penelitian ini juga dapat dibuktikan bahwa Perceived Service Quality memiliki pengaruh terhadap Purchase Intention. Pada hubungan ini, minat beli calon pelanggan atau Purchase Intention timbul disebabkan hasil dari persepsi tentang kualitas layanan yang sudah terbentuk dengan pelayanan yang diberikan oleh KPR bersubsidi terhadap calon pelanggan dan perasaan yang diterima oleh calon pelanggan tersebut terhadap KPR bersubsidi. Jadi calon pelanggan dapat memiliki minat beli terhadap KPR bersubsidi. Pada hasil penelitian ini ditemukan bahwa pengaruh tersebut merupakan hasil uji $T$-statistics dengan nilai 4,559, yaitu diatas 1,96. Sehingga diketahui bahwa Perceived Service Quality mempengaruhi minat beli dari calon pelanggan KPR bersubsidi.

Selain itu apabila dilihat dari nilai path coefficient, hubungan dari Perceived Service Quality menuju Purchase Intention sebesar 0,364. Pengaruh Perceived Service Quality kepada Purchase Intention lebih besar daripada Word of Mouth secara langsung. Persepsi dari kualitas layanan yang diterima oleh calon pelanggan KPR bersubsidi dapat memunculkan minat beli dari calon pelanggan KPR bersubsidi tersebut. Mulai dari pelayanan yang diberikan, informasi yang diberikan hingga lingkungan yang nyaman membuat Purchase Inttention dapat meningkat.

Secara keseluruhan pembahasan hipotesis diatas mampu menjawab rumusan masalah pada penelitian ini. Hubungan antar konsep dapat diterima dengan diperkuat oleh data hasil observasi. Keseluruhan variabel memiliki hubungan signifikan kecuali hubungan langsung Word of Mouth terhadapPurchase Intention. Hal ini membuktikan bahwa Brand Image dan Perceived Service Quality sudah menjadi variabel dengan nilai invervening sempurna dalam bidang perkreditan rumah ini untuk bisa menciptakan minat beli dari calon pelanggan. Cara pemasaran dengan menggunakan Word of Mouth saja masih belum dapat mempengaruhi minat beli secara signifikan. Sehingga diperlukan variabel lainnya untuk mendukung Word of Mouth seperti Brand Image serta Perceived Service Quality sehingga minat beli calon pelanggan KPR bersubsidi dapat meningkat.

\section{KESIMPULAN DAN SARAN}

\section{A. Kesimpulan}

Dari pembahasan di atas mengenai penelitian program KPR bersubsidi dapat disimpulkan bahwa Word of Mouth yang positif merupakan sebuah aspek yang sangat penting yang harus dimiliki oleh program
KPR. Karena telah terbukti melalui hasil penelitian tersebut, bahwa dengan adanya Word of Mouth yang positif akan memberi dampak besar yang positif juga terhadap Brand Image dan Perceived Service Quality di mana kedua variabel tersebut sangat berperan penting sebagai intervening dalam menciptakan Purchase Intention pada calon pelanggan KPR bersubsidi.

KPR bersubsidi dapat memberikan pengalaman yang baik terhadap pelanggan yang mengambil program KPR sehingga persepsi pelanggan yang pernah mengambil program KPR bersubsidi dapat merasa puas dan dapat menyebarkan Word of Mouth yang positif terhadap masyarakat lain yang berpotensi menjadi calon pelanggan dari KPR bersubsidi di masa yang akan datang. Dengan Word of Mouth yang positif maka akan menjadikan calon konsumen dapat membentuk persepsi yang baik juga terhadap KPR bersubsidi.

Peneliti selanjutnya dapat mengembangkan penelitian dengan menambah variabel diluar variabel yang digunakan dalam penelitian ini. Variabel yang mungkin bisa ditambahkan pada penelitian selanjutnya adalah MarketOrientation atau orientasi pasar yang menjadi strategi perusahaan dalam mengambil tindakan implementasi lapangan. Penelitian tersebut akan melihat pengaruh dari strategi MarketOrientation terhadap Brand Image dan Perceived Service Quality. Sehingga dapat dilihat kedepannya bagaimana implementasi yang dilakukan KPR bersubsidi secara langsung kepada masyarakat yang berpotensial menjadi calon pelanggan KPR bersubsidi.

\section{DAFTAR PUSTAKA}

Abdillah, W., \& Hartono, J. (2015). Partial Least Square (PLS) Alternatif Structural Equation Modeling (SEM) dalam Penelitian Bisnis. Yogyakarta: Andi Offset.

Blackwell, R., Miniard, P., \& Engel, J. (2001). Consumer Behaviour (9th ed.). Ohio: South-Western

Charo, N., Sharma, P., Shaikh, S., Haseeb, A., \& Sufya, M. Z. (2015). Determining the Impact of Ewom on Brand Image and Purchase Intention through Adoption of Online Opinions. International Journal of Humanities and Management Sciences, 3(1), 41-46.

Churchill, Gilbert A. 2005. Basic Marketing Research. Fourth Edition. Edisi Bahasa Indonesia (alih bahasa oleh E. Koswara, Dira Salam, dan Alvin Ruzhendi). Erlangga. Jakarta.

Detik finance, (2015). Ini Daftar Bank Penyalur KPR Subsidi 2015. https://finance.detik.com/properti/ 2847649/ini-daftar-bank-penyalur-kpr-subsidi2015. 
Grace, D. and O'Cass, A. (2005). Examining the Effects of Service Brand Communications on Brand Evaluation. Journal of Product and Brand Management. 14(2): 106-116.

Keller, K. L. (1993). Conceptualizing, measuring, and managing customer-based brand equity. Journal Marketing, 57, 1-22.

Properti, (2015). KPR BERSUBSIDI: Pemerintah Jajaki Kerjasama dengan Multifinance. http:/properti.bisnis.com/read/20151128/48/496614/ kpr-bersubsidi-pemerintah-jajaki-kerjasamadengan-multifinance.

Solomon, M. R. (2002). Consumer Behavior. USA: Prentice Hall International, Inc.

Sugiyono. (2007). Metode Penelitian Kuantitatif, Kualitatif, dan $R \& D$. Bandung: Alfabeta.

Zeithaml, V.A. \& Bitner, M.J. (2000). Service marketing: Integrating customer focus across the firm (2nd ed). New York: Irwin McGrawHill Publishing Company. 